Notes

\title{
Micellar Electrokinetic Capillary Chromatography of Porphinato Chelates as a Spectrophotometric Approach to Sub-Femtomole Detection of Metal Chelates
}

\author{
Tohru SAItoH*, Hitoshi Hoshino** and Takao YotsuYANAGI** \\ *Laboratory of Analytical Chemistry, Faculty of Engineering, Hokkaido University, \\ Sapporo 060, Japan \\ **Department of Molecular Chemistry and Engineering, Tohoku University, Aoba, Sendai 980, Japan
}

Keywords Micellar electrokinetic capillary chromatography, sub-femtomole detection, porphyrin chelate, spectrophotometry

Liquid chromatography (LC) is a powerful tool in trace metal analysis ${ }^{1-3}$, especially in cases where the available quantity of samples is strictly limited, e.g. clinical examination, air pollution monitoring, and quality control in the electronics industry. Although the current sensitivity is high, it is often limited by peak broadening due to the large elution volume used and slow mass-transfer kinetics. In fact, the LC column is an effective dilution device. ${ }^{4}$

A powerful alternative seems to be the micellar electrokinetic capillary chromatography (MECC) system in which the electroosmotic delivery of a mobile aqueous phase with a micellar pseudo-stationary phase is utilized; this system was first described by Terabe and coworkers. $^{5-7}$ In this type chromatography, an almost ideal plug-flow velocity profile of electroosmotic fluid ${ }^{8}$ and a micellar pseudo-stationary phase of colloidal dimension dispersed in a bulk aqueous phase provide extremely high theoretical plate numbers (more than $2 \times 10^{5}$ plates $\left./ 60 \mathrm{~cm}, \quad H E T P=(2-4) \mu \mathrm{m}\right) .5,6$ Excellent success of the MECC system has been demonstrated for the separation of phenols ${ }^{5}$, amino acids ${ }^{7}, B_{6}$ vitamers 9 , oligonucleotides $^{10}$, and metal chelates ${ }^{11}$, as well as a theoretical bases for the separation processes presented. $6,12,13$

Although such extremely high efficiency of the MECC (sharpness of peaks) can undoubtedly afford an improvement of the spectrophotometric detection limits (D.L.), there is a possible disadvantage associated with the minute detector volume and short light path length. In the case of the oncolumn absorbance detection mode, the detector light path is as long as the diameter of the capillary used (typically $0.05 \mathrm{~mm}$ ), which is by a factor of $1 / 200$ shorter than that of ordinary $10 \mathrm{~mm}$ cells. Nonetheless, indeed, the very low detection limit on a mass basis (1.4 fmol for the 4-(2-pyridylazo)resorcinolato$\mathrm{Cr}$ (III) chelate) has been suggested. ${ }^{11}$

An investigation has thus been conducted to assess the attainable D.L. of metals with the MECC-spectrophotometric detection system using water-soluble porphines as precolumn labeling agents, since they have enormous great molar absorption coefficients $(\varepsilon \simeq$ $7 \times 10^{5} \mathrm{~cm}^{-1} \mathrm{M}^{-1}$ ) at the Soret absorption bands. ${ }^{14}$ Among the porphine analogs examined, $\alpha, \beta, \gamma, \delta$-tetrakis(4carboxyphenyl)porphine (TCPP) was found to be one of the most promising reagents for MECC application using a sodium dodecyl sulfate (SDS) micellar solution.

The present work describes the first access to the subfemtomole detection of metal chelates in solution with a spectrophotometric means coupled with the MECC separation scheme without any preconcentration processes.

\section{Experimental}

The MECC system used in this work is basically similar to that described by Terabe $e$ al. ${ }^{5}$ A fused silica glass capillary tube $(0.05 \mathrm{~mm}$ bore $\times 850 \mathrm{~mm}$ in length, from Scientific Glass Engineering Inc.) was used. A constant current supply of a Shimadzu isotachophoresis (IP-2A) with platinum electrodes was used as a highvoltage DC power unit. A spectrophotometric detector (UVIDEC 100-IV from JASCO) was operated at 0.16 or 0.005 absorbance unit full-scale (aufs) range at $422 \mathrm{~nm}$. A minor modification of the detector was devised to fix the capillary onto the proper position in place of an ordinary $8 \mu$ flow cell. An entrance slit of $0.05 \mathrm{~mm} \times$ $1.0 \mathrm{~mm}$ made of aluminum foil was fitted just to the capillary tube at $150 \mathrm{~mm}$ from the negative end. Data acquisition was carried out with an LC data processor (Shimadzu Chromatopak C-R3A).

The capillary column was filled with a micellar solution comprising $0.02 \mathrm{M}$ sodium dodecyl sulfate (SDS), $0.05 \mathrm{M}$ imidazole, $0.05 \mathrm{M} \mathrm{NaH} \mathrm{PO}_{4}$, and 
$0.0125 \mathrm{M} \mathrm{Na}_{2} \mathrm{~B}_{4} \mathrm{O}_{7}$ at $\mathrm{pH} 7.0$. Introduction of the sample solution into the capillary, to $3 \mathrm{~mm}$ from the positive end $(6 \mathrm{nl})$, was achieved by siphonic action. The driving current was set at $25 \mu \mathrm{A}$ with a separation voltage of $16.5 \mathrm{kV}$. The chromatography was run at $25 \pm 1^{\circ} \mathrm{C}$ in a safety box with an interlock system.

Basically, the reported conditions for TCPP chelate formation reactions were followed. ${ }^{15,16}$ Catalysts, $\mathrm{Hg}$ (II) ion ( $4 \times 10^{-6} \mathrm{M}$ as nitrate) and pyridine $(0.01 \mathrm{M})$ were added to facilitate complexation reactions with the metal ions examined (within $20 \mathrm{~min}$ ) in a borate buffer solution at pH 9.2. ${ }^{16}$ The appropriate amounts of SDS, imidazole and the pH-buffer. salts were added to the sample solutions to provide a similar bulk composition to the filling micellar solution. Since TCPP chelates are somewhat light-sensitive, amber flasks were used for the sample preparation.

\section{Results and Discussion}

A typical chromatogram for some TCPP chelates is shown in Fig. 1. The base-line resolved separation of the TCPP chelates is quite successfully achieved with MECC. The elution order of the chelates is similar to that obtained by ordinary reversed-phase HPLC on an ODS column. ${ }^{16}$ However, for the present no cause for the seriously leading peaks of TCPP and the $\mathrm{Cu}(\mathrm{II})$ chelate in this MECC can be suggested.

In the HPLC system, the peak resolution of Mn(III) and $\operatorname{Co}$ (III) was successfully improved by adding pyridine $(0.01 \mathrm{M})$ into the eluent. ${ }^{16}$ In the MECC scheme, for the benefit of the pH control at 7.0, $0.05 \mathrm{M}$ imidazole, in place of pyridine, was dissolved in the filling

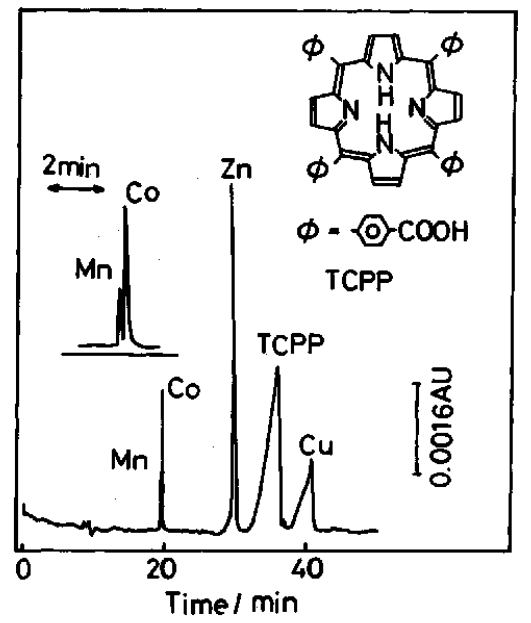

Fig. 1 MECC separation of metal TCPP chelates. Filling solution: $0.02 \mathrm{M}$ SDS, $0.05 \mathrm{M}$ imidazole, $0.05 \mathrm{M} \mathrm{NaH}_{2} \mathrm{PO}_{4}$ and $0.0125 \mathrm{M} \mathrm{Na}_{2} \mathrm{~B}_{4} \mathrm{O}_{7}$, at $\mathrm{pH}$ 7.0. Applied voltage and current: $16.5 \mathrm{kV}$ and $25 \mu \mathrm{A}$. Injection volume: $6 \mathrm{nl}$. Detection wavelength: $422 \mathrm{~nm}$. Concentration of each metal ion: $1 \times 10^{-5} \mathrm{M}$. micellar solution. The addition of imidazole gives rise to an enhanced retention of the $\mathrm{Co}$ (III) chelate via a favorable partition into the SDS micellar pseudo-phase as the result of the possible coordination of imidazole molecules on the axial sites of this TCPP chelate.

Owing to the high inertness of the TCPP chelates, the MECC system can be run without the addition of TCPP in the mobile aqueous phase; this assures a high sensitivity for the chelates with minimal background fluctuation (inherent system noise), about $5 \times 10^{-5}$ absorbance.

The Zn(II)-TCPP chelate shows excellent peak shape and a greatest $\varepsilon$ value of $6.78 \times 10^{5} \mathrm{M}^{-1} \mathrm{~cm}^{-1}$ at $422 \mathrm{~nm} ;{ }^{15,16}$ it was thus employed for a further examination of the attainable D.L. By contrast, TCPP chelates of the $\mathrm{Mn}$ (III) and $\mathrm{Co}$ (III) ions have somewhat small $\varepsilon$ values, even at their Soret bands $\left(1.02 \times 10^{5}\right.$ at $434 \mathrm{~nm}$ and $2.82 \times 10^{5}$ at $468 \mathrm{~nm}$, respectively ${ }^{16}$ ).

Figure 2 shows a peak near the D.L. (0.005 aufs, $S /$ $N=3$ ) for the $\mathrm{Zn}$ (II)-TCPP chelate at $80 \mathrm{nM}$, which was obtained by a serial dilution of the stock solution of the chelate. This concentration is translated into the minimum detectable amount of $4.8 \times 10^{-16} \mathrm{~mol}$ of the chelate $\left(2.9 \times 10^{8}\right.$ molecules, $\left.31 \mathrm{fg} \mathrm{Zn}\right)$ in a $6 \mathrm{nl}$ sample solution. Surprisingly, this absolute D.L. for $\mathrm{Zn}$ is fairly comparable to that of mass spectrometry ${ }^{17}$, and still lower than those of atomic fluorescence $(40 \mathrm{fg})^{18}$ or emission spectrometry $(100 \mathrm{fg}) .{ }^{19}$ In addition, even by laser fluorescence detection, D.L. for a porphyrin derivative of mesoporphine IX dimethylester was reported to be $8 \times 10^{-16} \mathrm{~mol} .^{20}$ It should be emphasized that this MECC system was designed to detect a very small amount of metals, not necessarily to determine their low concentrations. In fact, the concentration basis D.L. (0.005 aufs, $S / N=3$ ) for the $\mathrm{Zn}$ (II)-TCPP chelate in a reversed-phase HPLC system (with a $10 \mathrm{~cm}$ flow cell) reaches $1.5 \mathrm{nM}$ in an injection volume of $100 \mu \mathrm{l} ; 16$ however, the absolute oncolumn D.L. (on a mass basis) is only $1.5 \times 10^{-13} \mathrm{~mol}(9.8 \mathrm{pg} \mathrm{Zn})$ in this case.

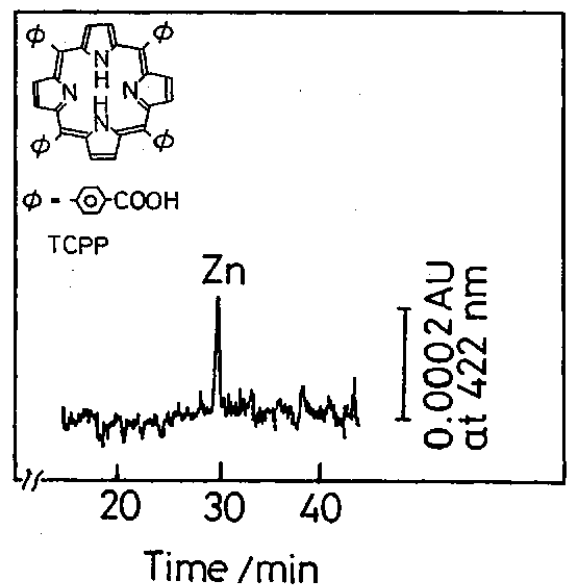

Fig. 2 Spectrophotometric response to an injection of $6 \mathrm{nl}$ of a $80 \mathrm{nM}$ solution $\left(4.8 \times 10^{-16} \mathrm{~mol}\right)$ of $\mathrm{Zn}$ (II) TCPP chelate at $422 \mathrm{~nm}$. Other conditions are the same as those in Fig. 1. 
A comparison of both the oncolumn D.L. data, [D.L. in HPLC] $/\left[\mathrm{D} . \mathrm{L}\right.$. in MECC] $=1.5 \times 10^{-13} / 4.8 \times 10^{-16}=313$, clearly reveals that the excellent efficiency of the MECC system provides a much greater sensitivity than does the conventional HPLC.

The approach described here is quite encouraging regarding the achievement of such an ultratrace detection of metals using a commonly available absorbance detector. It is stressed that this detection scheme coupled with MECC is perfectly compatible with a multielemental purpose. We believe that the greatly increased sensitivity in combination with the ultrasmall sample size will find unique applications in various fields of trace metal chemistry.

\section{References}

1. F. Walters, LC Magazine, 3, 1056 (1986).

2. A. R. Timerbaev, O. M. Petruhkin and Yu. A. Zolotov, Fresenius' Z. Anal. Chem., 327, 87 (1987).

3. B. Steinbrech, J. Liq. Chromatogr., 10, 1 (1987).

4. B. L. Karger and R. W. Giese, Anal. Chem., 50, 1048A (1978).

5. S. Terabe, K. Otsuka, K. Ichikawa and T. Ando, Anal. Chem., 56, 111 (1984).

6. S. Terabe, K. Otsuka and T. Ando, Anal. Chem., 57, 834 (1985).
7. K. Otsuka, S. Terabe and T. Ando, J. Chromatogr., 332, 219 (1985).

8. A. Watanabe and M. Tagawa, J. Colloid Interface Sci., 75, $218(1980)$.

9. D. E. Burton, M. J. Sepaniak and M. P. Maskarinec, J. Chromatogr. Sci, 24, 347 (1986).

10. A. S. Cohen, S. Terabe, J. A. Smith and B. L. Karger, Anal. Chem., 59, 1021 (1987).

11. T. Saitoh, H. Hoshino and T. Yotsuyanagi, $J$. Chromatogr., 469, 175 (1989).

12. D. W. Armstrong, Sep. Purif. Methods, 14, 213 (1985).

13. J. P. Forey, Anal. Chem., 62, 1302 (1990).

14. K. L. Cheng, K. Ueno and T. Imamura, "Handbook of Organic Analytical Reagents", p. 355, CRC Press, Boca Raton, 1982.

15. H. Ishii, H. Koh and K. Satoh, Nippon Kagaku Kaishi, $1980,1919$.

16. S. Igarashi, A. Obara, H. Adachi and T. Yotsuyanagi, Bunseki Kagaku, 35, 829 (1986).

17. M. Murozumi, S. Nakamura, H. Yokoyama, K. Chaki, N. Tsuya and K. Fukuda, Bunseki Kagaku, 35, 759 (1986).

18. H. Massmann, Spectrochim. Acta, 23B, 215 (1968).

19. W. B. Dodge III and R. O. Allen, Anal. Chem., 53, 1279 (1981).

20. L. W. Hershberger, J. B. Callis and G. D. Christian, Anal. Chem., 51, 1444 (1979).

(Received January 31, 1991)

(Accepted March 19, 1991) 